\title{
Association of Gender with Survival in Melanoma In Situ of the Head and Neck: A National Database Study
}

\author{
Vignesh Ramachandran ${ }^{1}$, Asad Loya ${ }^{2}$, Kevin Phan ${ }^{3}$ \\ 1. Dermatology, Baylor College of Medicine, Houston, USA 2. Medicine, Baylor College of Medicine, Houston, USA 3. \\ Dermatology, Liverpool Hospital, Sydney, AUS
}

Corresponding author: Vignesh Ramachandran, vig.ramachandran@gmail.com

\section{Abstract \\ Introduction}

While prior studies have addressed the gender-specific survival of malignant melanoma, such investigation is lacking for melanoma in situ (MIS) and for the sun-exposed head and neck areas. Understanding the role of patient characteristics on disease prognosis is essential in determining optimal patient treatment and follow-up. We conducted a retrospective cohort study of patients diagnosed with MIS of the head and neck to assess the association of gender with long-term survival.

\section{Methods}

First primary cases of MIS diagnosed between 1998 and 2015 were extracted from the National Cancer Institute's Surveillance, Epidemiology, and End Results (SEER) database. Cox regression analysis adjusting for demographic, tumor, and treatment characteristics was used to evaluate all-cause and cancer-specific mortality risks.

\section{Results}

After adjusting for demographic, tumor, and treatment data, males demonstrated significantly poorer overall survival (hazard ratio [HR] 1.484; 95\% confidence interval [CI] 1.332, 1.653; $\mathrm{P}<0.001$ ) and cancer-specific survival (HR 1.571; 95\% CI 1.056, 2.338; $\mathrm{P}=0.026$ ) compared to their female counterparts.

\section{Conclusion}

Proposed reasons for these findings include gender-based hormonal influence on cancer growth and development, gender-specific health utilization behaviors, and gender-based cosmetic impact of cutaneous malignancies. These findings do have limitations, including its retrospective nature, possible upgrading of MIS diagnoses during the study period, miscoding, and inability to account of

Received 11/19/2019

Review began 11/28/2019 Review ended 02/06/2020 Published 02/09/2020

() Copyright 2020 Ramachandran et al. This is an open access article distributed under the terms of the Creative Commons Attribution License CC-BY 4.0., which permits unrestricted use, distribution, and reproduction in any medium, provided the original author and source are credited. lifestyle/modifiable/environmental risk factors. Nevertheless, it suggests a gender-specific survival difference, which may be further investigated and considered as part of clinician awareness, influence patient counseling, and screening for such patients.

Categories: Dermatology, Otolaryngology, Epidemiology/Public Health

Keywords: melanoma in situ, head and neck, survival, gender, association, database, seer, otolaryngology, mis, dermatology

\section{Introduction}

Melanoma is a potentially fatal form of skin cancer and its prognosis sharply declines from in situ (stage 0) to stage 4 [1]. Current research focuses on prognostic factors and associations related to survival in melanoma, but such literature is often lacking for melanoma in situ (MIS) [2]. Such studies have documented the gender-specific survival advantage of females in early stage (stage 1) melanoma [3,4]. However, such investigation is lacking for MIS and for melanoma of the head and neck, the most common presenting location of melanomas [5]. Herein, we utilize the National Cancer Institute's Surveillance, Epidemiology, and End Results (SEER) database to investigate the association of gender with survival in patients with MIS of the head and neck.

\section{Materials And Methods}

We conducted a retrospective analysis using the SEER database, which provides data on approximately $34.6 \%$ of the United States population [6]. Primary cases of MIS (1998-2015) were identified using the International Classification of Diseases for Oncology Third Edition (ICD-O-3) histological codes for MIS $(8,720 / 2)$, MIS regressing (8,723/2), nodular MIS (8,721/2), balloon cell MIS (8,722/2), amelanotic MIS $(8,730 / 2)$, MIS in junctional nevus $(8,740 / 2)$, superficial spreading MIS $(8,743 / 2)$, acral lentiginous MIS 
(8,744/2), desmoplastic MIS (8,745/2), mucosal lentiginous MIS (8,746/2), MIS in compound nevus (8,760/2), MIS in giant pigmented cell $(8,761 / 2)$, epithelioid and spindle cell MIS $(8,770 / 2)$, epithelioid cell MIS $(8,771 / 2)$, and spindle cell MIS $(8,772 / 2)$. Cases were extracted without "malignant" field selected in the SEER database with the designation "/2," which reflects the following characteristics as per the SEER morphology classification: carcinoma in situ, intraepithelial, noninfiltrating, or noninvasive. ICD-O-3 topographical codes were further used to limit cases to the head and neck region, specifically as face and scalp or neck [7]. Demographic, tumor, treatment, and survival characteristics were extracted. Univariate and multivariate Cox regression analyses were conducted to determine all-cause and cancer-specific mortality risks. SPSS software (version 25, IBM Corp., Armonk, NY) was used to conduct all statistical analyses. A P-value of $<0.05$ was used to determine statistical significance.

\section{Results}

A total of 9,881 cases of MIS of the head and neck were identified over a mean follow-up period of 76.6 $( \pm 57.0)$ months. Additionally, $68.7 \%(6,787 / 9,881)$ of the overall cohort were male. Demographic, tumor, and treatment characteristics are displayed in Table 1 . The 10 -year overall survival (OS) was $79 \%$ for females, compared to $74 \%$ for males. After adjusting for demographic, tumor, and treatment data (found in Table 1), male subjects demonstrated significantly poorer OS (hazard ratio [HR] 1.484; 95\% confidence interval [CI] 1.332 , 1.653; $\mathrm{P}<0.001$ ) and cancer-specific survival (HR 1.571; $95 \%$ CI 1.056, 2.338; $\mathrm{P}=0.026$ ) compared to their female counterparts (Table 2). The female subgroup is the reference group given its higher 10-year survival; thus, it is used as the reference for the Cox regression analysis, which necessitates comparison to a reference group to compute HRs for unadjusted and adjusted survival in males.

\begin{tabular}{|c|c|c|c|c|c|c|c|c|}
\hline & & \multicolumn{7}{|l|}{ Sex } \\
\hline & & \multicolumn{2}{|c|}{ Female } & \multicolumn{2}{|l|}{ Male } & \multicolumn{2}{|l|}{ Total } & \multirow{2}{*}{$\begin{array}{l}\text { Chi-square } \\
\text { P-value }\end{array}$} \\
\hline & & $\mathrm{N}$ & $\%$ & $\mathrm{~N}$ & $\%$ & $\mathrm{~N}$ & $\%$ & \\
\hline \multirow{3}{*}{ Age group } & $0-64$ years & 1429 & $46.2 \%$ & 3066 & $45.2 \%$ & 4495 & $45.5 \%$ & \\
\hline & $65-74$ years & 731 & $23.6 \%$ & 1845 & $27.2 \%$ & 2576 & $26.1 \%$ & \\
\hline & $75+$ years & 934 & $30.2 \%$ & 1876 & $27.6 \%$ & 2810 & $28.4 \%$ & \\
\hline \multirow{4}{*}{ Race } & White & 2803 & $90.6 \%$ & 6206 & $91.4 \%$ & 9009 & $91.2 \%$ & $0.010^{*}$ \\
\hline & Black & 7 & $0.2 \%$ & 11 & $0.2 \%$ & 18 & $0.2 \%$ & \\
\hline & Other & 25 & $0.8 \%$ & 22 & $0.3 \%$ & 47 & $0.5 \%$ & \\
\hline & Unknown & 259 & $8.4 \%$ & 548 & $8.1 \%$ & 807 & $8.2 \%$ & \\
\hline \multirow{2}{*}{ Hispanic ethnicity } & Non-Hispanic & 2981 & $96.3 \%$ & 6647 & $97.9 \%$ & 9628 & $97.4 \%$ & \\
\hline & Hispanic & 113 & $3.7 \%$ & 140 & $2.1 \%$ & 253 & $2.6 \%$ & \\
\hline \multirow{5}{*}{ Marital status at diagnosis } & Married or domestic partner & 1268 & $41.0 \%$ & 3659 & $53.9 \%$ & 4927 & $49.9 \%$ & \\
\hline & Single (never married) & 270 & $8.7 \%$ & 476 & $7.0 \%$ & 746 & $7.5 \%$ & \\
\hline & Divorced /separated & 199 & $6.4 \%$ & 201 & $3.0 \%$ & 400 & $4.0 \%$ & \\
\hline & Widowed & 390 & $12.6 \%$ & 203 & $3.0 \%$ & 593 & $6.0 \%$ & \\
\hline & Unknown & 967 & $31.3 \%$ & 2248 & $33.1 \%$ & 3215 & $32.5 \%$ & \\
\hline \multirow{4}{*}{ Reporting source } & Hospital inpatient /outpatient /clinic & 1685 & $54.5 \%$ & 3634 & $53.6 \%$ & 5319 & $53.9 \%$ & 0.691 \\
\hline & Physicians office /private medical practitioner & 989 & $32.0 \%$ & 2177 & $32.1 \%$ & 3166 & $32.1 \%$ & \\
\hline & Laboratory only & 384 & $12.4 \%$ & 889 & $13.1 \%$ & 1273 & $12.9 \%$ & \\
\hline & Other & 34 & $1.1 \%$ & 84 & $1.2 \%$ & 118 & $1.2 \%$ & \\
\hline \multirow{2}{*}{ Primary site } & Face & 2552 & $82.5 \%$ & 4928 & $72.6 \%$ & 7480 & $75.7 \%$ & \\
\hline & Scalp /neck & 542 & $17.5 \%$ & 1859 & $27.4 \%$ & 2401 & $24.3 \%$ & \\
\hline \multirow[b]{3}{*}{ Laterality } & Unilateral & 2450 & $79.2 \%$ & 5049 & $74.4 \%$ & 7499 & $75.9 \%$ & \\
\hline & Bilateral & 5 & $0.2 \%$ & 14 & $0.2 \%$ & 19 & $0.2 \%$ & \\
\hline & Not a paired site & 447 & $14.4 \%$ & 1380 & $20.3 \%$ & 1827 & $18.5 \%$ & \\
\hline
\end{tabular}




\section{Cureus}

\begin{tabular}{|c|c|c|c|c|c|c|c|c|}
\hline & Midline & 40 & $1.3 \%$ & 79 & $1.2 \%$ & 119 & $1.2 \%$ & \\
\hline & Unknown & 152 & $4.9 \%$ & 265 & $3.9 \%$ & 417 & $4.2 \%$ & \\
\hline \multirow{2}{*}{ Diagnostic confirmation } & Positive histology & 3075 & $99.4 \%$ & 6744 & $99.4 \%$ & 9819 & $99.4 \%$ & 0.909 \\
\hline & Other & 19 & $0.6 \%$ & 43 & $0.6 \%$ & 62 & $0.6 \%$ & \\
\hline \multirow{3}{*}{ Surgery type } & WLE & 1657 & $53.6 \%$ & 3696 & $54.5 \%$ & 5353 & $54.2 \%$ & 0.680 \\
\hline & MMS & 823 & $26.6 \%$ & 1757 & $25.9 \%$ & 2580 & $26.1 \%$ & \\
\hline & No surgery & 614 & $19.8 \%$ & 1334 & $19.7 \%$ & 1948 & $19.7 \%$ & \\
\hline \multirow{5}{*}{ LN biopsy } & LN removed & 3 & $0.1 \%$ & 16 & $0.2 \%$ & 19 & $0.2 \%$ & 0.179 \\
\hline & Sentinel LN biopsy & 8 & $0.3 \%$ & 17 & $0.3 \%$ & 25 & $0.3 \%$ & \\
\hline & Both & 1 & $0.0 \%$ & 3 & $0.0 \%$ & 4 & $0.0 \%$ & \\
\hline & None & 2396 & $77.4 \%$ & 5369 & $79.1 \%$ & 7765 & $78.6 \%$ & \\
\hline & Unknown /NA & 686 & $22.2 \%$ & 1382 & $20.4 \%$ & 2068 & $20.9 \%$ & \\
\hline \multirow{3}{*}{ Tumor size } & $<1 \mathrm{~cm}$ & 627 & $20.3 \%$ & 1385 & $20.4 \%$ & 2012 & $20.4 \%$ & 0.985 \\
\hline & $>1 \mathrm{~cm}$ & 8 & $0.3 \%$ & 17 & $0.3 \%$ & 25 & $0.3 \%$ & \\
\hline & Unknown & 2459 & $79.5 \%$ & 5385 & $79.3 \%$ & 7844 & $79.4 \%$ & \\
\hline \multirow{3}{*}{ Tumor ulceration } & Not present & 1962 & $63.4 \%$ & 4352 & $64.1 \%$ & 6314 & $63.9 \%$ & 0.326 \\
\hline & Present & 8 & $0.3 \%$ & 29 & $0.4 \%$ & 37 & $0.4 \%$ & \\
\hline & Unknown & 1124 & $36.3 \%$ & 2406 & $35.5 \%$ & 3530 & $35.7 \%$ & \\
\hline
\end{tabular}

TABLE 1: Demographic, tumor, and treatment characteristics of patients with melanoma in situ of the head and neck regions.

${ }^{*} \mathrm{p}<0.05$.

MMS, Mohs micrographic surgery; WLE, wide local excision, LN, lymph node.

\begin{tabular}{|c|c|c|c|c|c|}
\hline & & \multicolumn{2}{|l|}{ Overall survival } & \multicolumn{2}{|c|}{ Cause-specific survival } \\
\hline & & $\mathrm{HR}(95 \% \mathrm{Cl})$ & P-value & HR (95\% Cl) & P-value \\
\hline \multirow{2}{*}{ Unadjusted analysis } & Female & Reference & Reference & Reference & Reference \\
\hline & Male & $1.215(1.098,1.344)$ & $<0.001$ & $1.401(0.964,2.037)$ & 0.077 \\
\hline \multirow{2}{*}{ Adjusted analysis } & Female & Reference & Reference & Reference & Reference \\
\hline & Male & $1.484(1.332,1.653)$ & $<0.001$ & $1.571(1.056,2.338)$ & 0.026 \\
\hline
\end{tabular}

TABLE 2: Unadjusted and adjusted Cox regression analysis.

\section{Discussion}

Improved melanoma survival for females has been reported in a large clinical trial and in European population-based studies [8,9]. However, these findings, to our knowledge, have yet to be investigated for MIS. In our study, we focus on the most common location of MIS (head and neck) in order to report clinically relevant findings. In doing so, we demonstrate that male patients have worsened melanoma-specific survival for MIS of the head and neck. Several mechanisms may account for this finding.

In their population-based study of 11,734 melanoma patients, Joosse et al. revealed a significant female advantage for melanoma-specific survival, lower risk of cancer progression (including reduced risk of lymph 
node and visceral metastases), and survival advantage even after first progression, although another study found no difference in survival between males and females with regards to metastatic disease $[4,8]$. To this end, they discussed the possibility of female gender-related factors that may portend a survival advantage or males may demonstrate a melanoma-stimulating factor [8]. Similarly, Molife et al. suggested that gender may influence distinct factors implicated in phases of disease in melanoma, primarily local primary tumor invasion [10]. Female steroids decrease invasion of melanoma cell lines through fibronectin, whereas male and adrenal steroids do not $[11,12]$. This may influence progression from MIS to higher stage melanoma which would result in worsened prognosis and survival.

Additionally, males, compared to females, are less likely to self-detect melanomas, have lower perceptions of skin cancer risk, and are less often utilize healthcare providers [1]. MIS represents an early detectable disease state that is readily-treated if care is sought early enough through self-detection or surveillance by a healthcare provider $[13,14]$. As such, intrinsic healthcare behaviors factors may portend worsened survival in males with MIS serving as a surrogate for possibly other cancers at large [14]. This may explain the worse male survival in seven different common malignancies presented by Molife et al. [10]. Furthermore, our study assessed a cosmetically sensitive region-the head and neck. Al-Dujaili et al. demonstrated that women pay close attention to skin health, especially of the face, which is where skin cancers often manifest [15]. This may lead to earlier detection and translate to cancer care-related behaviors portending improved outcomes

\section{Conclusions}

The limitations of our study include its retrospective nature, possible upgrading of MIS diagnoses during the study period, miscoding, and inability to account of lifestyle, modifiable, and environmental risk factors. While cases were extracted strictly by SEER morphology codes, upgrading of malignancies could be possible and not accounted for during the time period of the survival analysis. Additionally, clinical practices vary by hospitals and facilities reporting to SEER. For instance, sentinal lymph node biopsy was performed for a small subset of our overall cohort. This practice is not commonplace for MIS disease. Nevertheless, this variable was included as part of our multivariate analysis along with a plethora of other variables in order to account for as many factors as possible.

Overall, MIS represents the earliest form of melanoma (stage 0), so identifying prognostic markers such as gender-specific differences in survival may heighten clinician awareness, influence patient counseling, and screening. Future studies would be well intended in identifying ways to mitigate gender-based disparities in melanoma survival.

\section{Additional Information \\ Disclosures}

Human subjects: Consent was obtained by all participants in this study. Animal subjects: All authors have confirmed that this study did not involve animal subjects or tissue. Conflicts of interest: In compliance with the ICMJE uniform disclosure form, all authors declare the following: Payment/services info: All authors have declared that no financial support was received from any organization for the submitted work. Financial relationships: All authors have declared that they have no financial relationships at present or within the previous three years with any organizations that might have an interest in the submitted work. Other relationships: All authors have declared that there are no other relationships or activities that could appear to have influenced the submitted work.

\section{References}

1. Balch CM, Gershenwald JE, Soong SJ, et al.: Final version of 2009 AJCC melanoma staging and classification . J Clin Oncol. 2009, 27:6199-6206. 10.1200/JCO.2009.23.4799

2. Mocellin S, Nitti D: Cutaneous melanoma in situ: translational evidence from a large population-based study. Oncologist. 2011, 16:896-903. 10.1634/theoncologist.2010-0340

3. Khosrotehrani K, Dasgupta P, Byrom L, Youlden DR, Baade PD, Green AC: Melanoma survival is superior in females across all tumour stages but is influenced by age. Arch Dermatol Res. 2015, 307:731-740. 10.1007/s00403-015-1585-8

4. Enninga EAL, Moser JC, Weaver AL, et al.: Survival of cutaneous melanoma based on sex, age, and stage in the United States, 1992-2011. Cancer Med. 2017, 6:2203-2212. 10.1002/cam4.1152

5. Shashanka R, Smitha BR: Head and neck melanoma. ISRN Surg. 2012, 2012:948302. 10.5402/2012/948302

6. Surveillance, Epidemiology, and End Results (SEER) Program (www.seer.cancer.gov) SEER*Stat Database: Incidence - SEER 18 Regs Research Data, Nov 2017 Sub (1973-2015) Katrina/Rita Population Adjustment Linked To County Attributes - Total U.S., 1969-2016 Counties, National Cancer Institute. DCCPS, Surveillance Research Program, released April. 2018, based on the November 2017 submission. (2018). Accessed: February 8, 2020: https://seer.cancer.gov/data-software/documentation/seerstat/nov2017/.

7. Phan K, Onggo J, Loya A: Mohs micrographic surgery versus wide local excision for head and neck melanoma-in-situ. J Dermatol Treat. 2019, 15:1-4. 10.1080/09546634.2019.1639605

8. Joosse A, de Vries E, Eckel R, et al.: Gender differences in melanoma survival: female patients have a decreased risk of metastasis. J Invest Dermatol. 2011, 131:719-726. 10.1038/jid.2010.354

9. Joosse A, Collette S, Suciu S, et al.: Superior outcome of women with stage I/II cutaneous melanoma: pooled 


\section{Cureus}

analysis of four European Organisation for Research and Treatment of Cancer phase III trials. J Clin Oncol. 2012, 20:2240-2247. 10.1200/JCO.2011.38.0584

10. Molife R, Lorigan P, MacNeil S: Gender and survival in malignant tumours. Cancer Treat Rev. 2001, 27:201209. 10.1053/ctrv.2001.0220

11. Dewhurst LO, Gee JW, Rennie IG, MacNeil S: Tamoxifen, $17 \mathrm{~b}$ estradiol and the calmodulin antagonist J8 inhibit human melanoma cell invasion through fibronectin. Br J Cancer. 1997, 75:860-868. 10.1038/bjc.1997.153

12. Richardson B, Price A, Wagner M, et al.: Investigation of female survival benefit in metastatic melanoma . $\mathrm{Br}$ J Cancer. 1999, 80:2025-2033. 10.1038/sj.bjc.6690637

13. Liu W, Dowling JP, Murray WK, et al.: Rate of growth in melanomas: characteristics and associations of rapidly growing melanomas. Arch Dermatol. 2006, 142:1551-1558. 10.1001/archderm.142.12.1551

14. Courtenay WH: Constructions of masculinity and their influence on men's well-being: a theory of gender and health. Soc Sci Med. 2000, 50:1385-1401. 10.1016/s0277-9536(99)00390-1

15. Al-Dujaili Z, Henry M, Dorizas AS, Sadick NS: Skin cancer concerns particular to women. Int J Womens Dermatol. 2015, 1:123-125. 10.1016/j.ijwd.2015.07.002 